\title{
Gout is associated with a higher risk of chronic renal disease in older adults: a retrospective cohort study of U.S. Medicare population
}

\author{
Jasvinder A. Singh ${ }^{1,2,3,4^{*}}$ (D) and John D. Cleveland ${ }^{2}$
}

\begin{abstract}
Background: Hyperuricemia and gout have been linked to chronic kidney disease (CKD). Whether the increased risk of CKD in gout is due to shared risk factors such as hypertension, diabetes or heart disease, or due to gout itself is not known. Studies in older adults, who tend to have a high incidence of CKD, are limited. Our objective was to assess whether gout was associated with incident CKD in older adults.

Methods: Using the $5 \%$ random sample of Medicare claims, we assessed whether gout is associated with higher risk of incident (new) CKD in adults 65 years or older, using multivariable-adjusted Cox regression analyses, adjusting for demographics (age, gender, race), medical comorbidity and common medications. We calculated hazard ratios (HR) and 95\% confidence interval (Cl). Sensitivity analyses varied comorbidity variable (models 2, 3), or limited CKD to the most specific codes.

Results: Of the 1,699,613 eligible people, 168,065 developed incident CKD; 150,162 people without gout and 17,903 people with gout. Respective crude incidence rates were 15.6 vs. 78.1 per 1000 person-years. We found that gout was associated with a higher risk of incident CKD in multivariable-adjusted analyses, HR was 3.05 (95\% Cl, 2.99, 3.10), with minimal attenuation in sensitivity analyses, with $\mathrm{HR} 2.96(95 \% \mathrm{Cl}, 2.91,3.01)$ (model 2, categorical Charlson-Romano) and $2.59(95 \% \mathrm{Cl}, 2.54,2.63)$ (model 3, individual Charlson-Romano comorbidities plus hypertension, heart disease, obesity, coronary artery disease). Sensitivity analyses that limited the CKD diagnostic codes to more specific codes, confirmed findings from the main models with respective HRs of $3.10(95 \% \mathrm{Cl}, 3.05$, 3.15; Model 1), 3.03 ( $95 \% \mathrm{Cl}, 2.97,3.08$; Model 2) and 2.60 (95\% Cl, 2.56, 2.65; Model 3).
\end{abstract}

Conclusion: Gout was associated with a 3-fold higher risk of CKD, confirmed in multiple sensitivity analyses. Future studies should provide insights into underlying mechanisms that are responsible for an increased CKD risk in gout.

Keywords: Chronic kidney disease, Gout, Older adults, Elderly, Risk

\section{Introduction}

One in seven Americans adults, or roughly 30 million people, have chronic kidney disease (CKD) [1]. The prevalence of CKD is even higher in the adults 65-74 years, at one in five men, and one in four women [1]. Treatment for kidney failure costs $6.7 \%$ of the total

\footnotetext{
* Correspondence: Jasvinder.md@gmail.com

${ }^{1}$ Medicine Service, VA Medical Center, 510, 20th street South, FOT 805B, Birmingham, AL 35233, USA

2Department of Medicine at School of Medicine, University of Alabama at Birmingham, 1720 Second Ave. South, Birmingham, AL 35294-0022, USA Full list of author information is available at the end of the article
}

Medicare budget to care for $<1 \%$ of the covered Medicare population [1]. CKD ranked 18th in the world in 2010 as the cause of death in the global burden of disease study [2]. Thus, CKD constitutes a significant public health burden.

Gout is an inflammatory arthritis characterized by hyperuricemia and monosodium crystal formation in joints and other tissue, which lead to local and systemic inflammation with up-regulation of cytokines such as interleukin-1 and others [3]. Systematic reviews and meta-analyses of observational studies linked hyperuricemia

(c) The Author(s). 2019 Open Access This article is distributed under the terms of the Creative Commons Attribution 4.0 International License (http://creativecommons.org/licenses/by/4.0/), which permits unrestricted use, distribution, and 
to the development of stage 3 chronic kidney disease (CKD) [4] and incident kidney disease defined as composite of CKD, end-stage renal disease (ESRD), albuminuria or elevated serum creatinine [5]. Animal studies support a role of hyperuricemia in the progression of renal disease [6]. A key unanswered question is whether gout increases the risk of new onset CKD and if so, does this risk vary by the key demographic and clinical characteristics.

\section{Methods}

\section{Data sources and study sample}

We used the 5\% Medicare claims for this cohort study obtained through the Centers for Medicare and Medicaid Services Chronic Condition Data Warehouse. Patients were eligible for this study if they Medicare beneficiaries enrolled in Medicare fee-for-service (Parts A, B) 2006-2012, and not enrolled in Medicare Advantage Plan (due to incomplete claims data) and lived in the U.S. from 2006 to 2012. The study was approved by the Institutional Review Board at the University of Alabama at Birmingham.

\section{Independent variable/outcome of interest}

The outcome of interest was incident chronic kidney disease (CKD)/kidney failure (referred to as CKD in this study), identified by the occurrence of two diagnoses for CKD at least 4-weeks apart in Medicare claims, identified with International Classification of Diseases, ninth revision, common modification (ICD-9-CM) codes, 582.xx, 583.xx, 585.xx, 586.xx or 588.xx, with an absence of any CKD code in the baseline 365-day period. This ICD-9-CM code based approach has been used to assess renal disease in the validated Charlson-Romano comorbidity index [7] (one of the most commonly used comorbidity index), and is being currently used by the U.S. Renal Data System Coordinating Center [8]; a similar set of codes is also used in Deyo-Charlson index [9], another adaptation of the Charlson index. This approach is valid with high specificity of $99 \%$ and moderate sensitivity of $70-88 \%$ [10] and a median positive predictive value of $78 \%$ [11]. These ICD-9 codes include all CKD stages of the National Kidney Foundation classification of CKD.

\section{Predictor of interest}

Gout was the main exposure of interest, i.e., the independent variable. We assessed the presence of gout based on the presence of gout diagnosis identified with ICD-9 code of 274.xx in two Medicare claims at least 4-weeks apart, a valid approach with sensitivity of $90 \%$ and specificity of $100 \%$ [12].

We included known or suspected confounders/risk factors for CKD in our study, namely, demographics (age, gender and race), medical comorbidity assessed with a validated claims-based Charlson-Romano comorbidity index
[7] (which includes diabetes, diabetes with complications, heart failure etc.), as well as hypertension, hyperlipidemia and coronary heart disease. We also included obesity as a covariate, realizing that it would be under-coded, considering the pros vs. cons. We also assessed for the use of cardiovascular drugs (statins, beta-blockers, diuretics, and angiotensin converting enzyme (ACE)-inhibitors), and gout drugs (allopurinol, febuxostat), as surrogate of cardiovascular disease and/or its severity, and/or their independent effects on pathways that contribute to inflammation and oxidative stress that can contribute to a potentially higher risk of CKD [13-15].

\section{Statistical analysis}

We compared the characteristics of patients with to those without incident CKD, and calculated crude incidence rates of incident CKD in people with vs. without gout. We used multivariable-adjusted Cox regression analyses to assess the association of gout (exposure) with incident CKD (outcome), adjusting for demographics (age, gender, race), comorbidity (Charlson-Romano comorbidity index), and medications used for cardiovascular diseases or gout (main model; model 1). Hazard ratios and 95\% confidence intervals $(\mathrm{CI})$ were calculated. We conducted additional sensitivity analyses to test the robustness of findings by: (1) modeling Charlson-Romano comorbidity index as a categorical variable (model 2) or with individual comorbidities instead of continuous score plus hypertension, heart disease, obesity, and coronary artery disease (model 3 ); and (2) limiting to renal disease codes of ICD-9 codes 582.xx and 585.xx, more specific for CKD, and examining the effect on hazard ratios from models 1-3.

Subgroup analyses were done by age, gender, race as well as by the presence/absence of diabetes, hypertension, and coronary heart disease, known common risk factors for CKD in the general population.

\section{Results}

Of the 1,699,613 eligible people, 168,065 developed incident CKD. Compared to people without gout, people with gout were 0.4 years younger, had higher medical comorbidity, hypertension, hyperlipidemia and coronary artery disease and were more likely to be male, African-American (Table 1).

Incident CKD developed in 150,162 people without gout and 17,903 people with gout, with crude respective incidence rates of 15.6 vs. 78.1 per 1000 person-years. Gout was associated with a higher hazard of incident CKD in multivariable-adjusted analyses, HR was 3.05 (95\% CI, 2.99, 3.10), with minimal attenuation in sensitivity analyses, with HR 2.96 (95\% CI, 2.91, 3.01) (model 2, categorical Charlson-Romano) and 2.59 (95\% CI, 2.54, 2.63) (model 3, Charlson-Romano comorbidities plus hypertension, heart disease, obesity, and coronary artery 
Table 1 Demographic and clinical characteristics of people with vs. without Gout

\begin{tabular}{|c|c|c|}
\hline & $\begin{array}{l}\text { No Gout } \\
(N=1,623,304)\end{array}$ & $\begin{array}{l}\text { Gout } \\
(N=76,309)\end{array}$ \\
\hline Age, Mean (SD) & $75.3(7.6)$ & $74.9(7.0)$ \\
\hline \multicolumn{3}{|l|}{ Gender, N (\%) } \\
\hline Male & $672,755(41.4 \%)$ & $44,740(58.6 \%)$ \\
\hline Female & $950,549(58.6 \%)$ & $31,569(41.4 \%)$ \\
\hline \multicolumn{3}{|l|}{ Race, N (\%) } \\
\hline White & $1,403,749(86.5 \%)$ & $63,434(83.1 \%)$ \\
\hline Black & $128,197(7.9 \%)$ & $8585(11.3 \%)$ \\
\hline Others & $91,358(5.6 \%)$ & $4290(5.6 \%)$ \\
\hline $\begin{array}{l}\text { Charlson-Romano comorbidity } \\
\text { score }^{2} \text {, Mean (SD) }\end{array}$ & $1.5(2.5)$ & $2.0(2.4)$ \\
\hline \multicolumn{3}{|l|}{$\begin{array}{l}\text { Charlson-Romano comorbidity } \\
\text { score, N (\%) }\end{array}$} \\
\hline 0 & $883,689(54.4 \%)$ & 28,407 (37.2\%) \\
\hline 1 & $163,358(10.1 \%)$ & $10,658(14.0 \%)$ \\
\hline$\geq 2$ & $576,257(35.5 \%)$ & $37,246(48.8 \%)$ \\
\hline \multicolumn{3}{|c|}{ Select Charlson-Romano comorbidities } \\
\hline Myocardial Infarction & $59,625(3.7 \%)$ & $4450(5.8 \%)$ \\
\hline Heart Failure & $172,489(10.6 \%)$ & $14,630(19.2 \%)$ \\
\hline Peripheral vascular disease & $148,616(9.2 \%)$ & $10,082(13.2 \%)$ \\
\hline Cerebrovascular disease & $152,599(9.4 \%)$ & $9046(11.9 \%)$ \\
\hline Dementia & $74,277(4.6 \%)$ & $1926(2.5 \%)$ \\
\hline Chronic pulmonary disease & $245,086(15.1 \%)$ & $15,297(20.0 \%)$ \\
\hline Connective tissue disease & $43,359(2.7 \%)$ & $3063(4.0 \%)$ \\
\hline Peptic ulcer disease & 29,277 (1.8\%) & $1923(2.5 \%)$ \\
\hline Mild liver disease & $7583(0.5 \%)$ & $533(0.7 \%)$ \\
\hline Diabetes & $280,819(17.3 \%)$ & $21,459(28.1 \%)$ \\
\hline $\begin{array}{l}\text { Diabetes with end organ } \\
\text { damage }\end{array}$ & $77,421(4.8 \%)$ & $5906(7.7 \%)$ \\
\hline Hemiplegia & $13,144(0.8 \%)$ & $634(0.8 \%)$ \\
\hline Hypertension & $752,833(46.4 \%)$ & $53,555(70.2 \%)$ \\
\hline Hyperlipidemia & $545,421(33.6 \%)$ & $37,898(49.7 \%)$ \\
\hline Coronary artery disease & $267,429(16.5 \%)$ & $21,123(27.7 \%)$ \\
\hline Obesity & 30,761 (1.9\%) & 3285 (4.3\%) \\
\hline
\end{tabular}

disease) (Table 2). Of all comorbidities, diabetes and hypertension were associated with highest HR of 1.71 (95\% CI, 1.69, 1.73) and 1.78 (95\% CI, 1.76, 1.81) for incident CKD in multivariable-adjusted analyses, respectively.

Sensitivity analyses that limited the ICD-9 codes to more specific codes for CKD, confirmed findings from the three models with HRs of 3.10 (95\% CI, 3.05, 3.15; Model 1), 3.03 (95\% CI, 2.97, 3.08; Model 2) and 2.60 (95\% CI, 2.56, 2.65; Model 3).

Subgroup analyses showed that association of gout with incident CKD differed statistically significantly by age, gender and race, interaction term $p$-values were < $0.0001,<0.0001$ and 0.004 , respectively (Table 3 ).

Subgroup analyses by key disease risk factor for incident CKD showed interesting findings and all interactions were statistically significant $(<0.0001)$. For example, in people without hypertension, diabetes or CAD, HRs of incident CKD with gout were, 4.29, 3.47 and 3.32, much higher than the respective HRs in people without each disease respectively, 2.38, 2.24 and 2.38 (Table 3).

\section{Discussion}

We found that gout was associated with 3-fold higher hazard of $C K D$, independent of other risk factors including demographics, medical comorbidity including diabetes, hypertension and cardiovascular disease and the use of medications for cardiovascular disease and gout. An important finding was that the strength of association of gout with incident CKD changed minimally in multiple sensitivity analyses and only decreased from 3.1-fold in the main model with demographics, numerical Charlson-Romano comorbidities and commonly used medications to 2.6-fold in the model that additionally adjusted for hypertension, hyperlipidemia, obesity and coronary artery disease and examined individual Charlson-Romano comorbidities. This indicates that our study finding was robust, i.e., gout was independently associated with incident CKD in adults 65 years or older after controlling for common risk factors for CKD, including hypertension, diabetes, heart disease, obesity, age, race, gender and other medical comorbidities.

We can only speculate about possible mechanisms, since lack of laboratory data in Medicare and the observational nature study did not allow us to investigate this further in our study. Gout is characterized by the formation of monosodium urate (MSU) crystals, which are phagocytosed by macrophages or monocytes, which lead to disruption of lysosome and the activation of NALP3 inflammasome [16]. This process results in the formation of IL-1 $\beta$ and other pro-inflammatory cytokines [3]. Innate immune system is also involved in the pathogenesis of CKD, as demonstrated in the following observations. NALP3 mRNA levels were increased and correlated with renal function in a variety of nondiabetic kidney diseases and chronic kidney disease [13, 15]. Activation of NALP3 inflammasome and secretion of IL-1 $\beta$ and IL-18 causes the development of tubulointerstitial disease in diabetic nephropathy [17]. Severity of proteinuria in diabetic patients correlates with protein expression of caspase-1, IL-1 $\beta$ and IL-18 in the proximal and distal tubules [18]. Increased serum IL-18 levels in patients with chronic kidney disease [14] and the correlation of urine IL-18 levels with disease activity in nephrotic syndrome indicates that pro-inflammatory cytokines may play a role in chronic kidney disease $[19,20]$. Therefore, a biological rationale exists for the association of gout with 
Table 2 Association of gout and other risk factors with Incident CKD

\begin{tabular}{|c|c|c|c|c|c|c|}
\hline & \multicolumn{2}{|c|}{ Multivariable-adjusted (Model 1)* } & \multicolumn{2}{|c|}{ Multivariable-adjusted (Model 2)* } & \multicolumn{2}{|c|}{ Multivariable-adjusted (Model 3)* } \\
\hline & $\mathrm{HR}(95 \% \mathrm{Cl})$ & $P$-value & HR $(95 \% \mathrm{Cl})$ & $P$-value & HR $(95 \% \mathrm{Cl})$ & $P$-value \\
\hline \multicolumn{7}{|l|}{ Age (in years) } \\
\hline $65-<75$ & Ref & & Ref & & Ref & \\
\hline $75-<85$ & $1.62(1.60,1.63)$ & $<0.0001$ & $1.60(1.58,1.62)$ & $<0.0001$ & $1.55(1.53,1.57)$ & $<0.0001$ \\
\hline$\geq 85$ & $2.26(2.23,2.30)$ & $<0.0001$ & $2.27(2.24,2.31)$ & $<0.0001$ & $2.24(2.21,2.27)$ & $<0.0001$ \\
\hline \multicolumn{7}{|l|}{ Gender } \\
\hline Male & Ref & & Ref & & Ref & \\
\hline Female & $0.78(0.77,0.79)$ & $<0.0001$ & $0.78(0.77,0.78)$ & $<0.0001$ & $0.76(0.75,0.76)$ & $<0.0001$ \\
\hline \multicolumn{7}{|l|}{ Race } \\
\hline White & Ref & & Ref & & Ref & \\
\hline Black & $1.38(1.36,1.40)$ & $<0.0001$ & $1.42(1.39,1.44)$ & $<0.0001$ & $1.30(1.28,1.32)$ & $<0.0001$ \\
\hline Other & $0.98(0.96,1.00)$ & 0.024 & $1.01(0.99,1.03)$ & 0.46 & $0.96(0.94,0.98)$ & $<0.0001$ \\
\hline $\begin{array}{l}\text { Charlson-Romano score, } \\
\text { per unit change }\end{array}$ & $1.22(1.21,1.22)$ & $<0.0001$ & N/A & & N/A & \\
\hline \multicolumn{7}{|l|}{ Charlson-Romano score } \\
\hline 0 & N/A & & Ref & & N/A & \\
\hline 1 & & & $2.33(2.30,2.37)$ & $<0.0001$ & & \\
\hline$\geq 2$ & & & $2.99(2.96,3.02)$ & $<0.0001$ & & \\
\hline Gout & $3.05(2.99,3.10)$ & $<0.0001$ & $2.96(2.91,3.01)$ & $<0.0001$ & $2.59(2.54,2.63)$ & $<0.0001$ \\
\hline
\end{tabular}

* Model 1 included Charlson-Romano score as a continuous variable; Model 2 replaced it with categorized Charlson-Romano score; and Model 3 replaced it with each of the 17 Charlson-Romano comorbidities. All models were also adjusted for medications for cardiovascular diseases (statins, beta-blockers, diuretics, ACEinhibitors) and for urate-lowering therapies for gout (allopurinol, febuxostat)

$N / A$ not applicable, HR Hazard ratio, $\mathrm{Cl}$ confidence interval, Ref referent category

Bold represents statistical significance, with a $P$-value $<0.05$

Table 3 Association of gout with Incident CKD, in pre-defined subgroup analyses by race, gender, and age

\begin{tabular}{|c|c|c|c|c|c|c|}
\hline & \multicolumn{2}{|c|}{ Multivariable-adjusted (Model 1) } & \multicolumn{2}{|c|}{ Multivariable-adjusted (Model 1) } & \multicolumn{2}{|c|}{ Multivariable-adjusted (Model 1) } \\
\hline & HR $(95 \% \mathrm{Cl})$ & $P$-value & HR $(95 \%$ Cl) & $P$-value & HR $(95 \%$ Cl) & $P$-value \\
\hline & Black & & White & & Other race & \\
\hline \multirow[t]{2}{*}{ Gout } & $3.06(2.93,3.21)$ & $<0.0001$ & $3.04(2.98,3.10)$ & $<0.0001$ & $3.13(2.91,3.37)$ & $<0.0001$ \\
\hline & Female & & Male & & & \\
\hline \multirow[t]{2}{*}{ Gout } & $3.18(3.09,3.26)$ & $<0.0001$ & $2.96(2.90,3.03)$ & $<0.0001$ & & \\
\hline & $65-75$ years & & $75-85$ years & & $>85$ years & \\
\hline \multirow[t]{2}{*}{ Gout } & $3.34(3.26,3.43)$ & $<0.0001$ & $2.87(2.80,2.95)$ & $<0.0001$ & $2.66(2.54,2.80)$ & $<0.0001$ \\
\hline & No Hypertension & & Hypertension & & & \\
\hline \multirow[t]{2}{*}{ Gout } & $4.29(4.15,4.44)$ & $<0.0001$ & $2.38(2.33,2.43)$ & $<0.0001$ & & \\
\hline & No Diabetes & & Diabetes & & & \\
\hline \multirow[t]{2}{*}{ Gout } & $3.47(3.40,3.54)$ & $<0.0001$ & $2.24(2.18,2.30)$ & $<0.0001$ & & \\
\hline & No CAD & & CAD & & & \\
\hline Gout & $3.32(3.25,3.39)$ & $<0.0001$ & $2.38(2.31,2.46)$ & $<0.0001$ & & \\
\hline
\end{tabular}

$P$-value for interactions were as follows

Race*gout interaction term, $p$-value 0.004

Sex ${ }^{*}$ gout interaction term, $p$-value $<0.0001$

Age $^{*}$ gout interaction term, $p$-value $<0.0001$

Hypertension*gout interaction term, $p$-value $<0.0001$

Diabetes*gout interaction term, $p$-value $<0.0001$

CAD*gout interaction term, $p$-value $<0.0001$

$H R$ Hazard ratio, $\mathrm{Cl}$ confidence interval

Hazard ratios that are significant with $p$-value $<0.05$ are in bold 
CKD. Future studies should assess whether interventions targeting these pathways can reduce the risk of CKD, slow down the progression of CKD or prevent CKD in the older adults with gout.

While we speculate that inflammation is one potential pathway that may underlie the association of gout with incident CKD, hyperuricemia might also contribute. Uric acid is primarily excreted as well by reabsorbed in the kidney. Urate may induce renal damage in its soluble (crystal-independent) or crystal form [21]. Soluble or crystalline urate can activate various pathways that lead to inflammatory, proliferative, and maladaptive changes in glomeruli (soluble urate only) and the tubulointerstitium [21]. Hyperuricemia has been considered to be a result of slowly progressive CKD [22, 23] by some, while others showed that hyperuricemia may be causative of CKD [2428]. Allopurinol and febuxostat, two urate-lowering therapies (ULTs), have a potential role in preserving renal function. Evidence from observational studies indicated that use of allopurinol use was associated with improved renal function or slower age-related decline in renal function in some [29-31] but not all [32-35] studies. Similar evidence supported potential improvement of renal function with febuxostat use including an observational study [36] and a small randomized study [37]. A systematic review concluded that ULT with allopurinol may retard the progression of CKD, but that randomized trials were needed [38], a conclusion we agree with.

Another novel observation was the variation in the strength of the association of gout with incident CKD by important patient characteristics such as diabetes and CAD, and especially by hypertension. In each case, gout had a much stronger association with incident CKD in the absence of the condition: DM vs. no DM, 2.24 vs. 3.47; CAD vs. no CAD, 2.38 vs. 3.32; and hypertension vs. no hypertension, 2.38 vs. 4.29 . These differences are not only statistically significant, but also clinically meaningful, considering that CKD is a common disease with a significant impact on patient morbidity and mortality. The HR of 4.3 of CKD with gout in the absence of hypertension is almost twice as much as the HR of 2.4 in the presence of hypertension. Much smaller interactions that were statistically significant were noted by age, gender and race. This is not surprising at all, since in the presence of hypertension, diabetes, heart disease, the pathogenic mechanisms of gout may play a smaller role in contributing to the risk of incident CKD. Regardless a hazard ratio of $>2$ is an impressive finding of an association from a multivariable-adjusted model.

Study limitations include misclassification bias due to the use of diagnostic codes. We did not rely on a single diagnostic code, but used a validated algorithm for defining incident CKD to reduce this potential bias. This definition of incident CKD has been used in several high-quality studies [39-42] and being currently used by the U.S. Renal Data System Coordinating Center [8]. We realize that this ICD-9-code based approach includes all CKD stages of the National Kidney Foundation classification of CKD. Since milder kidney disease such as the CKD stage 2 likely has different outcomes than CKD stages 3-5, future studies need to investigate the risk of different stages of CKD in larger patient samples. Inclusion of CKD stage 2 in our ICD-9 approach may also lead to over-ascertainment of clinically significant CKD compared to the existing literature that relies on estimates GFR or creatinine. Some codes in our CKD definition are not specific, therefore we conducted sensitivity analyses limiting to codes specific for CKD, with min$\mathrm{imal} / \mathrm{no}$ attenuation of the hazard ratios. We attempted to minimize confounding bias by including several confounders and known risk factors for chronic renal disease, including diabetes, hypertension, hyperlipidemia, heart disease, age, race, gender etc. [43, 44]. However, we were unable to control for other minor risk factors such as smoking, and genetics due to the absence of these data in Medicare data; and the use of non-steroidal anti-inflammatory drugs (NSAIDs) since the majority use in the U.S. is non-prescription, which is not available in the Medicare database. We did not control for the use of angiotension II receptor antagonists, which are nephroprotective. Medicare data does not include laboratory data, and therefore in-depth investigation of serum urate levels, or association with various stages of CKD based on estimated glomerular filtration rate could not be performed.

Study strengths include robustness of estimates in multiple sensitivity analyses, use of a representative sample of the U.S. elderly 65 years or older, and a large sample size.

\section{Conclusion}

In conclusion, we found that the presence of gout was associated with a 3-fold higher risk of CKD, after controlling for demographics, comorbidity and cardiovascular and gout medication use. We also noted that this risk differed statistically significantly by age, gender and race, and both statistically significantly and clinically meaningfully by the presence of diabetes and CAD, and especially by hypertension. These observations improve our current understanding of renal disease in people with gout. Future studies need to elucidate the key pathogenic pathways responsible for reduced renal function in people with gout.

\footnotetext{
Abbreviations

ACE: angiotensin converting enzyme; CAD: coronary artery disease; $\mathrm{Cl}$ : confidence interval; CKD: chronic kidney disease; HR: Hazard ratio; ICD-9CM: International Classification of Diseases, ninth revision, common modification; MSU: monosodium urate crystals; SD: standard deviation
} 


\section{Acknowledgements}

I thank several patients in the gout clinic, who raised important questions about the effect of gout on the heart, that led us to design this study to answer the question.

\section{Funding}

This material is the result of work supported by research funds from the Division of Rheumatology at the University of Alabama at Birmingham and the resources and use of facilities at the Birmingham VA Medical Center, Birmingham, Alabama, USA. The funding body did not play any role in design, in the collection, analysis, and interpretation of data; in the writing of the manuscript; and in the decision to submit the manuscript for publication.

\section{Availability of data and materials}

We are ready to share the data with colleagues, after obtaining appropriate permissions from the University of Alabama at Birmingham (UAB) Ethics Committee, related to HIPAA and Privacy policies.

\section{Authors' contributions}

JAS designed the study, developed study protocol, reviewed analyses and wrote the first draft of the paper. JDC performed the data abstraction and data analyses. Both authors revised the manuscript, read, and approved the final manuscript.

\section{Ethics approval and consent to participate}

The University of Alabama at Birmingham's Institutional Review Board approved this study and all investigations were conducted in conformity with ethical principles of research. The IRB waived the need for an informed consent for this database study.

\section{Consent for publication}

Not required.

\section{Competing interests}

JAS has received research grants from Takeda and Savient and consultant fees from Savient, Takeda, Regeneron, Merz, Iroko, Bioiberica, Fidia, Crealta/ Horizon and Allergan pharmaceuticals, WebMD, UBM LLC, National Institute of Health and the American College of Rheumatology. JAS owns stock options in Amarin pharmaceuticals and Viking therapeutics. JAS serves as the principal investigator for an investigator-initiated study funded by Horizon pharmaceuticals through a grant to DINORA, Inc., a 501 (c)(3) entity. JAS is a member of the executive of OMERACT, an organization that develops outcome measures in rheumatology and receives arms-length funding from 36 companies; a member of the American College of Rheumatology's (ACR) Annual Meeting Planning Committee (AMPC); Chair of the ACR Meet-the-Professor, Workshop and Study Group Subcommittee; and a member of the Veterans Affairs Rheumatology Field Advisory Committee. JAS is the editor and Director of the UAB Cochrane Musculoskeletal Group Satellite Center on Network Meta-analysis. JDC has no relevant financial conflicts. There are no non-financial competing interests for either author.

\section{Publisher's Note}

Springer Nature remains neutral with regard to jurisdictional claims in published maps and institutional affiliations.

\section{Author details}

${ }^{1}$ Medicine Service, VA Medical Center, 510, 20th street South, FOT 805B, Birmingham, AL 35233, USA. 'Department of Medicine at School of Medicine, University of Alabama at Birmingham, 1720 Second Ave. South, Birmingham, AL 35294-0022, USA. Division of Epidemiology at School of Public Health, University of Alabama at Birmingham, 1720 Second Ave. South, Birmingham, AL 35294-0022, USA. ${ }^{4}$ University of Alabama at Birmingham, Faculty Office Tower 805B, 510 20th Street S, Birmingham, AL 35294-0022, USA.
Received: 20 March 2018 Accepted: 3 March 2019

Published online: 15 March 2019

\section{References}

1. World Kidney Day: Chronic Kidney Disease. 2015; http://www. worldkidneyday.org/faqs/chronic-kidney-disease/. Accessed 5 Mar 2019.

2. Jha V, Garcia-Garcia G, Iseki K, Li Z, Naicker S, Plattner B, Saran R, Wang AY, Yang CW. Chronic kidney disease: global dimension and perspectives. Lancet. 2013;382(9888):260-72.

3. Dalbeth $\mathrm{N}$, Haskard DO. Mechanisms of inflammation in gout. Rheumatology (Oxford). 2005:44(9):1090-6.

4. Li L, Yang C, Zhao Y, Zeng X, Liu F, Fu P. Is hyperuricemia an independent risk factor for new-onset chronic kidney disease? A systematic review and meta-analysis based on observational cohort studies. BMC Nephrol. 2014; 15(1):122.

5. Li YL, Wang L, Li J, Huang Y, Yuan WM. The correlation between uric acid and the incidence and prognosis of kidney diseases: a systematic review and meta-analysis of cohort studies. Zhonghua Nei Ke Za Zhi. 2011;50(7):555-61.

6. Kang DH, Nakagawa T, Feng L, Watanabe S, Han L, Mazzali M, Truong L, Harris $\mathrm{R}$, Johnson RJ. A role for uric acid in the progression of renal disease. J Am Soc Nephrol. 2002:13(12):2888-97.

7. Romano PS, Roos LL, Jollis JG. Adapting a clinical comorbidity index for use with ICD-9-CM administrative data: differing perspectives. J Clin Epidemiol. 1993;46(10):1075-9; discussion 1081-1090.

8. Collins AJ, Chen SC, Gilbertson DT, Foley RN. CKD surveillance using administrative data: impact on the health care system. Am J Kidney Dis. 2009:53(3 Suppl 3):S27-36.

9. Deyo RA, Cherkin DC, Ciol MA. Adapting a clinical comorbidity index for use with ICD-9-CM administrative databases. J Clin Epidemiol. 1992;45(6):613-9.

10. Romano PS, Mark DH. Bias in the coding of hospital discharge data and its implications for quality assessment. Med Care. 1994;32(1):81-90.

11. Vlasschaert ME, Bejaimal SA, Hackam DG, Quinn R, Cuerden MS, Oliver MJ, lansavichus A, Sultan N, Mills A, Garg AX. Validity of administrative database coding for kidney disease: a systematic review. Am J Kidney Dis. 2011;57(1):29-43.

12. Singh JA, Hodges JS, Toscano JP, Asch SM. Quality of care for gout in the US needs improvement. Arthritis Rheum. 2007;57(5):822-9.

13. Chen K, Zhang J, Zhang W, Zhang J, Yang J, Li K, He Y. ATP-P2X4 signaling mediates NLRP3 inflammasome activation: a novel pathway of diabetic nephropathy. Int J Biochem Cell Biol. 2013;45(5):932-43.

14. Ortega LM, Fornoni A. Role of cytokines in the pathogenesis of acute and chronic kidney disease, glomerulonephritis, and end-stage kidney disease. Int J Interfer Cytok Mediat Res. 2010;2(1):49-62.

15. Vilaysane A, Chun J, Seamone ME, Wang W, Chin R, Hirota S, Li Y, Clark SA, Tschopp J, Trpkov K, et al. The NLRP3 inflammasome promotes renal inflammation and contributes to CKD. J Am Soc Nephrol. 2010;21(10):1732-44.

16. Martinon F, Petrilli V, Mayor A, Tardivel A, Tschopp J. Gout-associated uric acid crystals activate the NALP3 inflammasome. Nature. 2006; 440(7081):237-41.

17. Fang L, Xie D, Wu X, Cao H, Su W, Yang J. Involvement of endoplasmic reticulum stress in albuminuria induced inflammasome activation in renal proximal tubular cells. PLoS One. 2013;8(8):e72344.

18. Martin-Rodriguez S, Caballo C, Gutierrez G, Vera M, Cruzado JM, Cases A, Escolar G, Diaz-Ricart M. TLR4 and NALP3 inflammasome in the development of endothelial dysfunction in uraemia. Eur J Clin Investig. 2015;45(2):160-9.

19. Matsumoto K, Kanmatsuse K. Increased urinary excretion of interleukin-17 in nephrotic patients. Nephron. 2002;91(2):243-9.

20. Lonnemann G, Novick D, Rubinstein M, Dinarello CA. Interleukin-18, interleukin-18 binding protein and impaired production of interferongamma in chronic renal failure. Clin Nephrol. 2003;60(5):327-34.

21. Johnson RJ, Bakris GL, Borghi C, Chonchol MB, Feldman D, Lanaspa MA Merriman TR, Moe OW, Mount DB, Sanchez Lozada LG, et al. Hyperuricemia, acute and chronic kidney disease, hypertension, and cardiovascular disease: report of a scientific workshop organized by the National Kidney Foundation. Am J Kidney Dis. 2018;71(6):851-65.

22. Jing J, Kielstein JT, Schultheiss UT, Sitter T, Titze SI, Schaeffner ES, McAdams-DeMarco M, Kronenberg F, Eckardt KU, Kottgen A, et al. Prevalence and correlates of gout in a large cohort of patients with 
chronic kidney disease: the German chronic kidney disease (GCKD) study. Nephrol Dial Transplant. 2014;30(4):613-21.

23. Juraschek SP, Kovell LC, Miller ER 3rd, Gelber AC. Association of kidney disease with prevalent gout in the United States in 1988-1994 and 20072010. Semin Arthritis Rheum. 2013;42(6):551-61.

24. Mazzali M, Kanellis J, Han L, Feng L, Xia YY, Chen Q, Kang DH, Gordon KL, Watanabe $\mathrm{S}$, Nakagawa T, et al. Hyperuricemia induces a primary renal arteriolopathy in rats by a blood pressure-independent mechanism. Am J Physiol Renal Physiol. 2002;282(6):F991-7.

25. Nakagawa T, Mazzali M, Kang DH, Kanellis J, Watanabe S, Sanchez-Lozada LG, Rodriguez-Iturbe B, Herrera-Acosta J, Johnson RJ. Hyperuricemia causes glomerular hypertrophy in the rat. Am J Nephrol. 2003;23(1):2-7.

26. Sanchez-Lozada LG, Tapia E, Avila-Casado C, Soto V, Franco M, Santamaria J, Nakagawa T, Rodriguez-lturbe B, Johnson RJ, Herrera-Acosta J. Mild hyperuricemia induces glomerular hypertension in normal rats. Am J Physiol Renal Physiol. 2002;283(5):F1105-10.

27. Chang HY, Tung CW, Lee PH, Lei CC, Hsu YC, Chang HH, Yang HF, Lu LC, Jong MC, Chen CY, et al. Hyperuricemia as an independent risk factor of chronic kidney disease in middle-aged and elderly population. Am J Med Sci. 2010;339(6):509-15

28. Obermayr RP, Temml C, Gutjahr G, Knechtelsdorfer M, Oberbauer R, KlauserBraun R. Elevated uric acid increases the risk for kidney disease. J Am Soc Nephrol. 2008;19(12):2407-13.

29. Pai BH, Swarnalatha G, Ram R, Dakshinamurty KV. Allopurinol for prevention of progression of kidney disease with hyperuricemia. Indian J Nephrol. 2013; 23(4):280-6.

30. Sezer S, Karakan S, Atesagaoglu B, Acar FN. Allopurinol reduces cardiovascular risks and improves renal function in pre-dialysis chronic kidney disease patients with hyperuricemia. Saudi J Kidney Dis Transpl. 2014;25(2):316-20.

31. Levy GD, Rashid N, Niu F, Cheetham TC. Effect of urate-lowering therapies on renal disease progression in patients with hyperuricemia. J Rheumatol. 2014;41(5):955-62.

32. Gores PF, Fryd DS, Sutherland DE, Najarian JS, Simmons RL. Hyperuricemia after renal transplantation. Am J Surg. 1988;156(5):397-400.

33. Chonchol M, Shlipak MG, Katz R, Sarnak MJ, Newman AB, Siscovick DS, Kestenbaum B, Carney JK, Fried LF. Relationship of uric acid with progression of kidney disease. Am J Kidney Dis. 2007;50(2):239-47.

34. Madero M, Sarnak MJ, Wang X, Greene T, Beck GJ, Kusek JW, Collins AJ, Levey AS, Menon V. Uric acid and long-term outcomes in CKD. Am J Kidney Dis. 2009;53(5):796-803.

35. Fessel WJ. Renal outcomes of gout and hyperuricemia. Am J Med. 1979; 67(1):74-82.

36. Singh JA, Akhras KS, Shiozawa A. Comparative effectiveness of urate lowering with febuxostat versus allopurinol in gout: analyses from large U.S. managed care cohort. Arthritis Res Ther. 2015;17(1):120.

37. Sircar D, Chatterjee S, Waikhom R, Golay V, Raychaudhury A, Chatterjee $S$, Pandey R. Efficacy of Febuxostat for slowing the GFR decline in patients with CKD and asymptomatic hyperuricemia: a 6-month, double-blind, randomized, placebo-controlled trial. Am J Kidney Dis. 2015;66(6):945-50

38. Bose B, Badve SV, Hiremath SS, Boudville N, Brown FG, Cass A, de Zoysa JR, Fassett RG, Faull R, Harris DC, et al. Effects of uric acid-lowering therapy on renal outcomes: a systematic review and meta-analysis. Nephrol Dial Transplant. 2014;29(2):406-13.

39. Singh JA, Yu S. Are allopurinol dose and duration of use nephroprotective in the elderly? A Medicare claims study of allopurinol use and incident renal failure. Ann Rheum Dis. 2016;76(1):133-9.

40. Foley RN, Murray AM, Li S, Herzog CA, McBean AM, Eggers PW, Collins AJ. Chronic kidney disease and the risk for cardiovascular disease, renal replacement, and death in the United States Medicare population, 1998 to 1999. J Am Soc Nephrol. 2005;16(2):489-95.

41. Winkelmayer WC, Schneeweiss S, Mogun H, Patrick AR, Avorn J, Solomon DH. Identification of individuals with CKD from Medicare claims data: a validation study. Am J Kidney Dis. 2005;46(2):225-32.

42. McClellan WM, Langston RD, Presley R. Medicare patients with cardiovascular disease have a high prevalence of chronic kidney disease and a high rate of progression to end-stage renal disease. J Am Soc Nephrol. 2004;15(7):1912-9.
43. Levin A. Identification of patients and risk factors in chronic kidney disease-evaluating risk factors and therapeutic strategies. Nephrol Dial Transplant. 2001;16(Suppl 7):57-60.

44. Haroun MK, Jaar BG, Hoffman SC, Comstock GW, Klag MJ, Coresh J. Risk factors for chronic kidney disease: a prospective study of 23,534 men and women in Washington County, Maryland. J Am Soc Nephrol. 2003; 14(11):2934-41.

\section{Ready to submit your research? Choose BMC and benefit from:}

- fast, convenient online submission

- thorough peer review by experienced researchers in your field

- rapid publication on acceptance

- support for research data, including large and complex data types

- gold Open Access which fosters wider collaboration and increased citations

- maximum visibility for your research: over $100 \mathrm{M}$ website views per year

At BMC, research is always in progress.

Learn more biomedcentral.com/submissions 